Available Online at : journal.stieamkop.ac.id/seiko

"Vol 3, No 1 (2019): July - Desember"

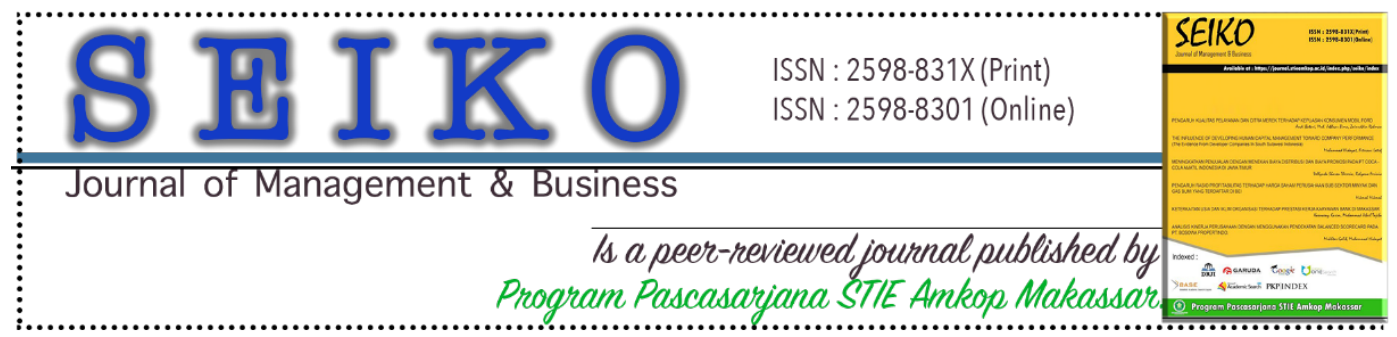

How to Cite:

Megawati Beddu, Rezki Nurbakti. (2019). PENGARUH METODE SERVIS QUALITY (SERQUAL) TERHADAP STRATEGI PEMASARAN OBJEK WISATA ALAM (STUDI KASUS OBJEK WISATA PANTAI WAKKA KABUPATEN PINRANG). SEIKO : Journal of Management \& Business, 3(1), $101-130$.

\title{
PENGARUH METODE SERVIS QUALITY (SERQUAL) TERHADAP STRATEGI PEMASARAN OBJEK WISATA ALAM (Studi Kasus Objek Wisata Pantai Wakka Kabupaten Pinrang)
}

\author{
Megawati Beddu \\ Akademi Sekretari Manajemen Amsir Asm Amsir \\ Email : megawatibeddu751@gmail.com \\ Rezki Nurbakti \\ Akademi Sekretari Manajemen Amsir Asm Amsir \\ Email : megawatibeddu751@gmail.com
}

\begin{abstract}
ABSTRAK
Penelitian ini bertujuan untuk mengetahui untuk mengetahui pengaruh variabel Servqual terhadap penentuan strategi pemasaran produk wisata pantai Wakka terhadap penentuan strategi pemasaran pada wisata alam pantai Wakka.Pnelitian ini merupakan deskriptif kuantitatif yaitu penelitian yang memberikan gambaran secara jelas dan sistematis mengenai data-data dan fakta-fakta yang ada dilapangan,seberapa besar pengaru servis quality terhadap strategi pemasaran dipantai Wakka.Penelitian ini dilakukan dengan metode kuantitatif, dengan melakukan observasi langsung dan penyebaran quesioner kepada wisatawan dengan tujuan khusus mengidentifikasi tingkat harapan dan tingkat kepuasan wisatawan terhadap objek wisata pantai wakka melalui pendekatan servqual.
\end{abstract}


Available Online at : journal.stieamkop.ac.id/seiko

"Vol 3, No 1 (2019): July - Desember"

Hasil penelitian berdasarkan olah data regresi berganda menunjukkan bahwa variable Tangibel $(X 1)$ dan variable reabiliy (X2) memiliki arah yang berlawanan sehingga tidak memberi pengaruh dan untuk variable responsive(X3),Assurance (X4) dan emphaty $(X 5)$ memiliki arah yang sama .berdasarkan hal tersebut dapat disimpulkan bahwa servis quality kurang berpengaruh terhadap strategi pemasaran yang mengakibatkan pantai wakka membutuhkan strategi pemasaran baru dalam mengembangkan pantai Wakka sebagai industri wisata.

Kata kunci : "Strategi Pemasaran, Servis Quality, Pantai Wakka"

\section{PENDAHULUAN}

Pantai Wakka dengan garis pantai yang panjang dan landai, menjadi daya tarik bagi wisatawan untuk datang menikmati pemandangan laut terutama di sore hari.Terletak di Kecamatan Cempa Desa Tadangpalie berjarak 30 km sebelah barat ibukota Kabupaten Pinrang,merupakan icon wisata yang potensial untuk dikembangkan. Potensi wisata di pantai Wakka, selain hamparan pasir putih yang luas, birunya air laut dan juga sejuknya angin sepoi - sepoi di tepi pantai, wisatawan juga dapat menikmati lezatnya ikan bakar lengkap dengan sambal dan nasi serta sayur, minum air kelapa muda dari kebun kelapa, aneka permainan air seperti banana boat, juga tersedia gasebong tradisional untuk beristirahat. Berdasarkan survey banyak wisatawan yang menyanyangkan kondisi wisata pantai Wakka seperti fasilitas pendukung kurang, tidak ada petugas berjaga di sekitar pantai. padahal sebagian besar pengunjung yang bermain di pantai adalah anak kecil berusia 3-7 tahun, sekitar pantai masih kotor, Akses jalan menuju pantai juga sempit yang menyebabkan kemacetan ketika terjadi lonjakan pengunjung dan lain sebagainya. Membuktikan bahwa potensi yang ada belum dikelola secara maksimal. Sehingga peneliti ingin merumuskan konsep pengembangan objek wisata pantai Wakka untuk mewujudkan linkage antara objek wisata yang satu dengan yang lain.

Untuk itu, dibutuhkan perubahan dalam mengembangkan pantai Wakka dengan menerapkan strategi yang efektif guna memanfaatkan kekuatan internal yang dimiliki dan memperhatikan faktor eksternalnya. Atas dasar inilah perlu adanya kajian penelitian strategi yang tepat dalam mengembangkan pariwisata di 
Available Online at : journal.stieamkop.ac.id/seiko "Vol 3, No 1 (2019): July - Desember"

Kabupaten Pinrang. Kajian penelitian strategi yang tepat untuk mengembangkan pariwisata pantai Wakka adalah dengan menggunakan Metode Servqual Gap 5 (Harapan dan persepsi ) yang terdiri dari Tangibel, Reliability, Responsive, Assurance dan Emphaty. Model ini berkaitan erat dengan model kepuasan konsumen dengan tujuan agar peneliti dapat mengidentifikasi dan menganalisa jenis strategi pemasaran yang dibutuhkan dalam pengembangan produk wisata pantai Wakka di kabupaten Pinrang.

\section{TINJAUAN PUSTAKA}

\section{State of The Art}

Beberapa penelitian yang berhubungan dengan pendekatan Service Quality( Servqual) diantara dilakukan oleh El Samen at.all (2012) tentang the impact of internal marketing on internal servis quality : A case study in Jordanian pharmaceutical company berdasarkan hasil penelitiannya diperoleh hasil bahwa internal marketing yang terdiri dari motivation dan reward system dapat meningkatkan kinerja dan signifikan mempengaruhi kualitas layanan terhadap dimensi tangible, assurance dan responsiveness. Effecttive employee's selection berpengaruh positif terhadap dimensi kualitas layanan internal terutama terhadap dimensi emphaty dan recruitment berpengaruh terhadap kualitas layanan yang mencakup tangible, responsiveness, assurance, reliability, dan emphaty dan penelitian yang dilakukan oleh Alifiana Hafidian Rizkiyani dan Fuad Achmadi dengan penelitian Strategi

Pemasaran Objek Wisata Dengan Pendekatan Servqual Mix Dan Quality Function Deployment (Qfd) (Studi Kasus Di Objek Wisata Pantai Talang Siring Kabupaten Pamekasan) Hasil dari analisis Servqual dan QFD menunjukkan bahwa prioritas utama dalam upaya perumusan strategi pemasaran yaitu: (1) konservasi mangrove untuk membantu pemulihan SDA dan dapat menjadi bank hidup ekosistem pantai, (2) mengadakan event culture tourism yang dilakukan secara rutin, (3) memberikan bekal edukasi kepada nelayan agar melakukan hal yang benar dalam melakukan aktivitasnya sehingga tidak merusak biota laut, (4) mengikuti event nasioanl dan internasional guna memperkenalkan potensi wisata, 
Available Online at : journal.stieamkop.ac.id/seiko "Vol 3, No 1 (2019): July - Desember"

dan (5) melakukan kegiatan promosi dari media cetak, membuat web khusus ODTW

\section{Manajemen Pemasaran}

Secara umum manajemen pemasaran dapat diartikan sebagai suatu seni dan ilmu untuk dapat memilih pasar sasaran, dan mendapatkan, mempertahankan, dan menumbuhkan pelanggan melalui penciptaan, penyampaian, dan pengkomunikasian nilai yang unggul kepada pelanggan" (Kolter dan Keller, 2009;62)

Lingkungan pemasaran dapat di bagi menjadi dua, yaitu: lingkungan internal dan lingkungan eksternal. 1) Lingkungan internal, Menurut Kotler (2010:69), salah satu hasil dari analisis lingkungan adalah ditemukannya peluang-peluang yang menarik, yang lainnya adalah dikenalinya kompetensi pokok yang bisa dimanfaatkan untuk meraih peluang tersebut. 2) Lingkungan eksternal, Menurut Kotler (2010:66), secara umum, perusahaan harus memantau kekuatan-kekuatan lingkungan makro yang pokok (demografi, ekonomi, teknologi, politik/hukum dan sosial/budaya) yang berpengaruh terhadap bisnisnya.

\section{Strategi Pemasaran}

Menurut Fandy Tjiptono dkk(2008:283) strategi pemasaran merupakan rencana yang menjabarkan ekspektasi perusahaan akan dampak dari berbagai aktivitas dan program pemasaran terhadap produk atau lini produknya di pasar sasaran tertentu. Dalam hal ini perusahaan dapat menggunakan dua atau lebih program pemasaran secara bersamaan,sebab setiap jenis program (seperti periklanan,promosi,penjualan,personal selling,layanan pelanggan atau pengembangan produk) memiliki pengaruh yang berbeda-beda terhadap permintaan.Oleh sebab itu dibutuhkan mekanisme yang dapat mengoordinasikan program-program pemasaran agar program-program itu sejalan dan terintegrasi dengan sinergetik.Mekanisme ini di sebut strategi pemasaran.

Unsur-unsur pokok dalam strategi pemasaran menurut Fandy Tjiptono dkk (2008:284) 
Available Online at : journal.stieamkop.ac.id/seiko

"Vol 3, No 1 (2019): July - Desember"

tersaji dalam tabel 1 dibawah ini :

Tabel 1.

\begin{tabular}{|l|l|}
\hline Unsur & Alternatif \\
\hline Pemilih pasar sasaran & Semua pembeli dipasar relevan \\
& Pembeli di beberapa segmen \\
& Pembeli di satu segmen ceruk pasar \\
\hline $\begin{array}{l}\text { Tipe permintaan yang ingin di } \\
\text { distimulasi }\end{array}$ & Permintaan primer \\
& - Di antara para pemakai baru \\
& - Di antara para pemakai saat ini \\
& Permintaan selektif \\
& - Dalam served market yang baru \\
& - Di antara pelanggan pesaing \\
& - Dalam basis pelanggan saat ini \\
\hline
\end{tabular}

Dalam industri pariwisata strategi pemasaran yang dapat dibuat meliputi pengembangan tempat dan aktivitas wisata, akomodasi, akses ke tujuan-tujuan wisata, sarana-sarana pendukung pariwisata, dan juga komunikasi pemasaran pariwisata yang efektif dan efisien.

c. Servqual

Model servqual yang dikembangkan oleh Parasuraman, Zeithaml, dan Berry dalam serangkaian penelitian banyak dijadikan acuan dalam riset manajemen dan pemasaran jasa termasuk pemasaran dalam pariwisata.

Wijaya (2011) mengemukakan bahwa service quality adalah sekelompok manfaat yang berdaya guna baik secara eksplisit maupun implisit atas kemudahan untuk mendapatkan barang maupun jasa. Kotler dan Keller (2009) mengemukakan bahwa service quality adalah kualitas dari pelayanan yang diberikan perusahaan kepada pelanggan.

Rini Alfatiyah (2018:2) Metode pengukuran kualitas pelayanan yang paling sering digunakan yaitu metode servqual yaitu menilai kualitas pelayanan suatu penyedia jasa berdasarkan lima dimensi kualitas jasa yang sering disebut Q-RATER. QRATER tersebut yaitu:

Tangibles (Bukti Fisik).

Meliputi penampilan fisik, peralatan, pekerja atau alat komunikasi. 
Available Online at : journal.stieamkop.ac.id/seiko

"Vol 3, No 1 (2019): July - Desember"

Reliability (Keandalan).

Yaitu kemampuan untuk memberikan pelayanan yang telah dijanjikan secara handal dan akurat.

Responsiveness (Daya Tanggap).

Yaitu keinginan untuk membantu pelanggan dan menyediakan layanan dengan cepat

d) Assurance (Jaminan).

Yaitu pengetahuan dan kesopanan karyawan dalam melayani pelanggan serta kemampuan mereka untuk menjaga kepercayaan pelanggan.

e) Emphaty (Empati).

Yaitu kepedulian, perhatian individu yang disediakan oleh perusahaan kepada pelanggan

Road Map Penelitian

Pada bagian ini menggambarkan mengenai alur Penelitian yang disajikan dalam bentuk bagan singkat dan jelas dibawah ini :

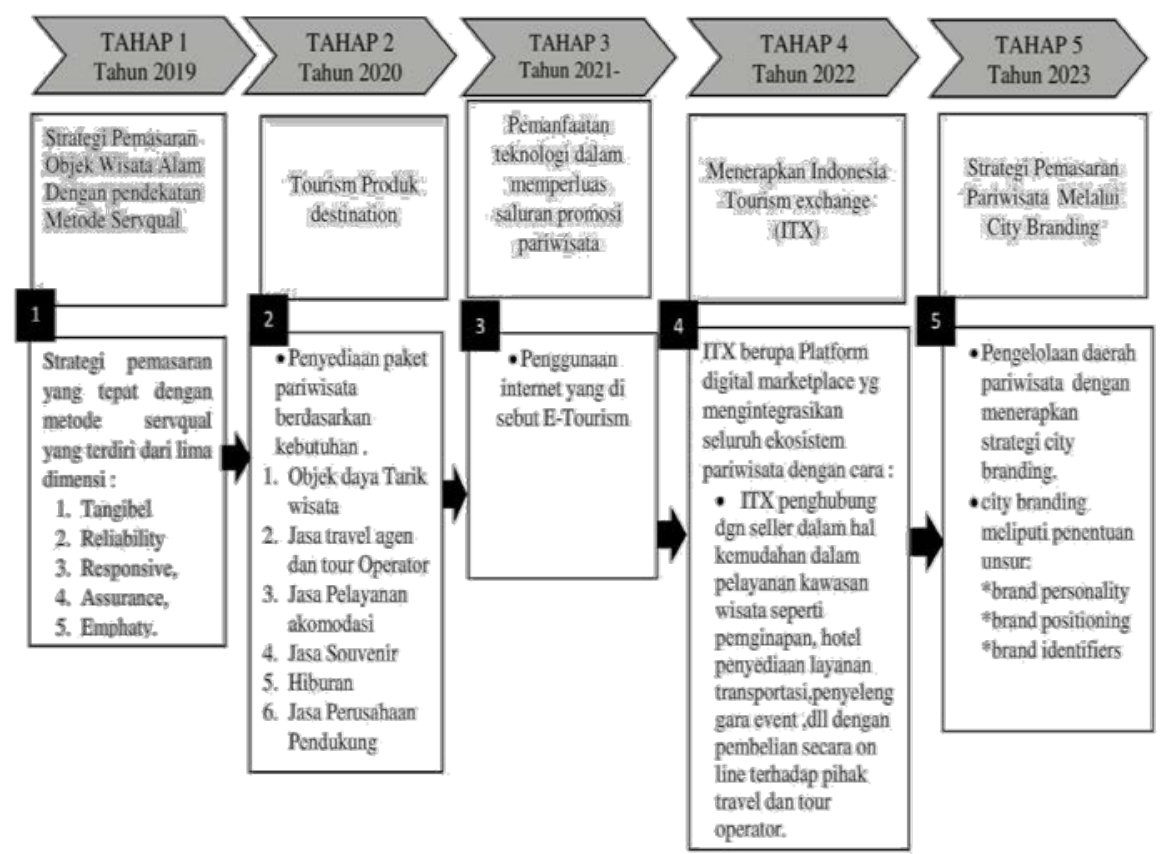

Gambar 1 . Road Map 
Available Online at : journal.stieamkop.ac.id/seiko

"Vol 3, No 1 (2019): July - Desember"

\section{METODE PENELITIAN}

Jenis penelitian ini adalah penelitian deskriptif kuantitatif dengan menggunakan pendekatan servqual merupakan pendekatan used - based apporoach (pendekatan berbasis pengguna). Penelitian akan dilaksanakan selama 10 bulan, yakni Maret 2019 hingga November 2109 di Pantai Wakka, Kecamatan Cempa Desa Tadangpalie.

\section{HASIL DAN PEMBAHASAN}

Uji Ketepatan Model

a. Validasi

Pengujian terhadap setiap instrument dilakukan sebelum melakukan regresi atau pengujian hipotesis dengan tujuan untuk mengetahui apakah instrument yang diajukan sudah sesuai atau mewakili terhadap hasil yang di inginkan pada penelitian. Uji validitas digunakan untuk mengukur sah atau valid tidaknya suatu instrument pada kuesioner (Ghozali 2009). Suatu kuesioner dikatakan valid jika pertanyaan pada kuesioner mampu mampu mengungkapkan sesuatu yang di ukur pada kuesioner tersebut

Validasi instrumen di lakukan dengan menggunakan korelasi Bivariate Pearson (Produk moment Pearson) dalam program statistic produks servis solution (SPSS 24). Analisis ini dengan cara mengkorelasikan masing-masing skor item pada setiap variable dengan skor total.Item-item pertanyaan yang bekorelasi signifikan dengan skor total menunjukkan item tersebut mampu memberikan dukungan dalam mengungkap apa yang ingin di ungkap peneliti.Dikatakan valid apabila $r$ hitung $\geq r$ tabel .

Dalam penelitian ini ,peneliti menggunakan 50 orang respondent maka diperoleh angka korelasi Pada $r$ tabel sebesar 0,279.Angka ini di peroleh dari $\mathrm{n}$-2 di mana $\mathrm{n}$ merupakan banyaknya jumlah respondent dengan tingkat signifikan 0,05.Dengan demikian apabila ada koefisien korelasi butir instrument berada di bawah 0,279 maka instrument tersebut dinyatakan tidak valid.

1) Instrumen Tangibel (X1) 
Available Online at : journal.stieamkop.ac.id/seiko "Vol 3, No 1 (2019): July - Desember"

Hasil uji validitas pada instrument tangibel (X1) dari sembilan pertanyaan ,setelah dilakukan analisis korelasi Bivariate Pearson antar jawaban setiap item pertanyaan dengan skor total,nilai korelasi dari semua item yang terdiri dari penyediaan lahan parkir,sarana komunikasi, sarana ibadah,loket,gazebo,kesediaan permainan air,sarana kuliner, souvenir, toilet ramah lingkungan.dapat dilihat pada tabel di bawah ini :

Tabel 2 Hasil Uji Validitas Instrumen Tangibel

\begin{tabular}{|c|c|c|c|c|c|}
\hline Variabel & Pertanyaan & $\begin{array}{c}\text { Korelasi } \\
\text { Item }\end{array}$ & $\begin{array}{c}\text { Nilai } \\
\text { Sig } \\
(2- \\
\text { Tiled) }\end{array}$ & r-Tabel & Kesimpulan \\
\hline \multirow[t]{9}{*}{ X1 } & $\begin{array}{c}\text { Pertanyaan } \\
1\end{array}$ & 0,973 & 0,000 & \multirow[t]{9}{*}{0,279} & Valid \\
\hline & Pertanyaan2 & 0,760 & 0,000 & & Valid \\
\hline & $\begin{array}{c}\text { Pertanyaan } \\
3\end{array}$ & 0,743 & 0,000 & & Valid \\
\hline & $\begin{array}{c}\text { Pertanyaan } \\
4\end{array}$ & 0,858 & 0,000 & & Valid \\
\hline & $\begin{array}{c}\text { Pertanyaan } \\
5\end{array}$ & 0,872 & 0,000 & & Valid \\
\hline & $\begin{array}{c}\text { Pertanyaan } \\
6\end{array}$ & 0,790 & 0,000 & & Valid \\
\hline & $\begin{array}{c}\text { Pertanyaan } \\
7\end{array}$ & 0,762 & 0,000 & & Valid \\
\hline & $\begin{array}{c}\text { Pertanyaan } \\
8\end{array}$ & 0,935 & 0,000 & & valid \\
\hline & $\begin{array}{c}\text { Pertanyaan } \\
9\end{array}$ & 0,850 & 0,000 & & Valid \\
\hline
\end{tabular}

Dari hasil uji validitas terhadap variable tangible berdasarkan tabel di atas dapat djelaskan bahwa sebagian besar butir pertanyaan yang digunakan dalam variable tersebut dinyatakan valid. Hal ini terbukti dari Sembilan item pertanyaan yang dicantumkan dalam kuesioner adalah valid. Berarti di simpulkan bahwa variable tangible dalam penelitian ini mempunyai pengaruh signifikan terhadap strategi pemasaran objek wisata pantai Wakka.Dimana pada tabel di atas $r$-tabel $\leq r$-hitung

2) Instrumen Reability (X2) 
Available Online at : journal.stieamkop.ac.id/seiko "Vol 3, No 1 (2019): July - Desember"

Hasil uji validitas pada instrument reability (X2 ) dari tujuh pertanyaan ,setelah dilakukan analisis korelasi Bivariate Pearson antar jawaban setiap item pertanyaan dengan skor total,nilai korelasi dari semua item yang terdiri dari kesesuain pelayanan,kecepatan dan ketepatan pelayanan, kebersihan dan kenyamanan,harga yang terjangkau,keaslian kawasan pantai,sarana kuliner, serta ketersediaan jasa pemandu handal, dapat dilihat pada tabel $3 \mathrm{di}$ bawah ini :

Tabel 3

Hasil Uji Validitas Instrumen Reability

\begin{tabular}{|c|c|c|c|c|c|}
\hline Variabel & Pertanyaan & Korelasi Item & $\begin{array}{l}\text { Nilai Sig } \\
\text { (2-Tiled) }\end{array}$ & r-Tabel & Kesimpulan \\
\hline \multirow[t]{7}{*}{$\mathrm{X} 2$} & $\begin{array}{c}\text { Pertanyaan } \\
1\end{array}$ & 0,367 & 0,000 & 0,279 & Valid \\
\hline & Pertanyaan2 & 0,286 & 0,000 & & Valid \\
\hline & $\begin{array}{c}\text { Pertanyaan } \\
3\end{array}$ & 0,416 & 0,000 & & Valid \\
\hline & $\begin{array}{c}\text { Pertanyaan } \\
4\end{array}$ & 0,485 & 0,000 & & Valid \\
\hline & $\begin{array}{c}\text { Pertanyaan } \\
5\end{array}$ & 0,418 & 0,000 & & Valid \\
\hline & $\begin{array}{c}\text { Pertanyaan } \\
6\end{array}$ & 0,568 & 0,000 & & Valid \\
\hline & $\begin{array}{c}\text { Pertanyaan } \\
7\end{array}$ & 0,350 & 0,000 & & Valid \\
\hline
\end{tabular}

Dari hasil uji validitas terhadap variable reability (X2) berdasarkan tabel di atas dapat djelaskan bahwa semua butir pertanyaan yang digunakan dalam variable tersebut dinyatakan valid. Berarti di simpulkan bahwa variable reability dalam penelitian ini mempunyai pengaruh signifikan terhadap strategi pemasaran objek wisata pantai Wakka.Dimana pada tabel di atas $r$ tabel $\leq$ r-hitung

3) Instrumen Responsive(X3) 
Available Online at : journal.stieamkop.ac.id/seiko "Vol 3, No 1 (2019): July - Desember"

Hasil uji validitas pada instrument Responsive $(\mathrm{X} 3)_{2}$ dari lima pertanyaan ,setelah dilakukan analisis korelasi Bivariate Pearson antar jawaban setiap item pertanyaan dengan skor total,nilai korelasi dari semua item pertanyaan yang terdiri dari perhatian serius dan cepat terhadap wisatawan yang mendapat masalah,pemberian informasi lengkap,tanggung jawab pengelola,memahami keinginan dan kebutuhan wisatawan,serta sikap antusias melayani wisatawan, dapat dilihat pada tabel 1.6 di bawah ini :

Tabel 4

Hasil Uji Validitas Instrumen Responsive (X3)

\begin{tabular}{|c|c|c|c|c|c|}
\hline Variabel & Pertanyaan & $\begin{array}{l}\text { Korelasi } \\
\text { Item }\end{array}$ & $\begin{array}{l}\text { Nilai Sig } \\
\text { (2-Tiled) }\end{array}$ & r-tabel & Kesimpulan \\
\hline \multirow[t]{5}{*}{$\mathrm{X} 2$} & $\begin{array}{c}\text { Pertanyaan } \\
1\end{array}$ & 0,460 & 0,000 & 0,279 & Valid \\
\hline & Pertanyaan2 & 0,407 & 0,000 & & Valid \\
\hline & $\begin{array}{c}\text { Pertanyaan } \\
3\end{array}$ & 0,422 & 0,000 & & Valid \\
\hline & $\begin{array}{c}\text { Pertanyaan } \\
4\end{array}$ & 0,462 & 0,000 & & Valid \\
\hline & $\begin{array}{c}\text { Pertanyaan } \\
5\end{array}$ & 0,481 & 0,000 & & Valid \\
\hline
\end{tabular}

Dari hasil uji validitas terhadap variable Responsive (X3) berdasarkan tabel di atas dapat djelaskan bahwa semua butir pertanyaan yang digunakan dalam variable tersebut dinyatakan valid.Kesimpulannya bahwa variable tangible dalam penelitian ini berpengaruh signifikan terhadap strategi pemasaran objek wisata pantai Wakka. Dimana pada tabel di atas $r$-tabel $\leq r$-hitung

4) Instrumen Assurance (X4) 
Available Online at : journal.stieamkop.ac.id/seiko "Vol 3, No 1 (2019): July - Desember"

\begin{abstract}
Hasil uji validitas pada instrument Assurance (X4) dari lima pertanyaan ,setelah dilakukan analisis korelasi Bivariate Pearson antar jawaban setiap item pertanyaan dengan skor total,nilai korelasi dari semua item pertanyaan yang terdiri dari kepercayaan pelayanan,jaminan asuransi,ketenangan dan kedamaian,kelancaran lalu lintas,kualitas produk yang terjamin yang dapat dilihat pada tabel 5 di bawah ini :
\end{abstract}

Tabel 5

Hasil Uji Validitas Instrumen Responsive (X3)

\begin{tabular}{|c|c|c|c|c|c|}
\hline Variabel & Pertanyaan & Korelasi Item & $\begin{array}{l}\text { Nilai Sig } \\
\text { (2-Tiled) }\end{array}$ & r-tabel & Kesimpulan \\
\hline \multirow[t]{5}{*}{$\mathrm{X} 2$} & $\begin{array}{c}\text { Pertanyaan } \\
1\end{array}$ & 0,348 & 0,000 & \multirow[t]{5}{*}{0,279} & Valid \\
\hline & Pertanyaan2 & 0,346 & 0,000 & & Valid \\
\hline & $\begin{array}{c}\text { Pertanyaan } \\
3\end{array}$ & 0,351 & 0,000 & & Valid \\
\hline & $\begin{array}{c}\text { Pertanyaan } \\
4\end{array}$ & 0,411 & 0,000 & & Valid \\
\hline & $\begin{array}{c}\text { Pertanyaan } \\
5\end{array}$ & 0,411 & 0,000 & & Valid \\
\hline
\end{tabular}

Dari hasil uji validitas terhadap variable Responsive (X3) berdasarkan tabel di atas dapat djelaskan bahwa semua butir pertanyaan yang digunakan dalam variable tersebut dinyatakan valid. Sehingga dapat disimpulkann bahwa variable Responsive (X3) dalam penelitian ini berpengaruh signifikan terhadap strategi pemasaran objek wisata pantai Wakka. Dimana pada tabel di atas $r$-tabel $\leq r$-hitung

5) Instrumen Emphaty (X5)

Hasil uji validitas pada instrument Emphaty (X5) dari lima pertanyaan yang di ajukan kepda respondent,setelah dilakukan analisis korelasi Bivariate Pearson antar jawaban setiap item pertanyaan dengan skor total,nilai korelasi dari semua item pertanyaan yang terdiri dari sikap yang sopan dan ramah,sikap bersahabat, sikap perhatian,kenyamanan pengunjung,memahami keinginan pengunjung dapat dilihat pada tabel 6 di bawah ini 
Available Online at : journal.stieamkop.ac.id/seiko

"Vol 3, No 1 (2019): July - Desember"

Tabel 6 Hasil Uji Validitas Instrumen Emphaty (X5

\begin{tabular}{|c|c|c|c|c|c|}
\hline Variabel & Pertanyaan & Korelasi Item & $\begin{array}{l}\text { Nilai Sig } \\
\text { (2-Tiled) }\end{array}$ & r-tabel & Kesimpulan \\
\hline \multirow[t]{5}{*}{$x 5$} & $\begin{array}{c}\text { Pertanyaan } \\
1\end{array}$ & 0,926 & 0,000 & 0,279 & Valid \\
\hline & Pertanyaan2 & 0,761 & 0,000 & & Valid \\
\hline & $\begin{array}{c}\text { Pertanyaan } \\
3\end{array}$ & 0,744 & 0,000 & & Valid \\
\hline & $\begin{array}{c}\text { Pertanyaan } \\
4\end{array}$ & 0,931 & 0,000 & & Valid \\
\hline & $\begin{array}{c}\text { Pertanyaan } \\
5\end{array}$ & 0,828 & 0,000 & & Valid \\
\hline
\end{tabular}

Dari hasil uji validitas terhadap variable Emphaty (X5) berdasarkan tabel di atas dapat djelaskan bahwa semua butir pertanyaan yang digunakan dalam variable tersebut dinyatakan valid. Sehingga dapat disimpulkan bahwa variable Emphaty (X5) dalam penelitian ini berpengaruh signifikan terhadap strategi pemasaran objek wisata pantai Wakka di kabupaten Pinrang. Dimana pada tabel di atas $r$-tabel $\leq r$-hitung

\section{b. Uji Reliabilitas}

Pada dasarnya uji reliabilitas dilakukan untuk menunjukkan sifat suatu alat ukur apakah alat ukur tersebut sudah cukup akurat atau belum,stabil atau konsisten dalam mengukur apa yang kita ukur.atau dengan kata lain menguji data yang kita peroleh dari hasil kuesioner yang kita bagikan.Dalam penelitian ini apakah instrument yang telah di ajukan cukup reliable,maka dilakukan dengan bantuan computer program SPSS 24 denga menggunakan metode konsistensi internal melalui teknik analisis Cronbach Alpha.Menurut I.anatut Toifah (2015) suatu variable dikatakan reliable jika nilai croncbah Alpha $\geq 0,60$ atau $60 \%$. Yang artinya semua pertanyaan yang di ajukan reliable sehingga dapat di ajukan untuk analisis selanjutnya. 
Available Online at : journal.stieamkop.ac.id/seiko

"Vol 3, No 1 (2019): July - Desember"

1). Instrumen Tangibel (X1)

Berikut hasil uji reabilitas instrument Tangibel dengan sembilan butir item pertanyaan adalah sebagai berikut:

Tabel 7

Hasil Uji Reablity instrument Tangibel

\begin{tabular}{ccc}
\hline Item & Cronbach Alpha & Keterangan \\
\hline Pertanyaan 1 & 0,759 & Reliabel \\
\hline Pertanyaan 2 & 0,764 & Reliabel \\
\hline Pertanyaan 3 & 0,770 & Reliabel \\
\hline Pertanyaan 4 & 0,768 & Reliabel \\
\hline Pertanyaan 5 & 0.764 & Reliabel \\
\hline Pertanyaan 6 & 0,768 & Reliabel \\
\hline Pertanyaan 7 & 0,773 & Reliabel \\
\hline Pertanyaan 8 & 0,760 & Reliabel \\
\hline Pertanyaan 9 & 0,763 & Reliabel \\
\hline \multicolumn{2}{c}{ Sumber : data hasil penelitian 2019 yang telah di olah }
\end{tabular}

Pada tabel di atas, hasil uji reliabilitas menunjukkan bahwa semua item pertanyaan pada variable tangible (X1) mempunyai nlai Cronbach Alpha di atas 0,60 sehingga dapat dikatakan bahwa semua pertanyaan dari kuesioner yang digunakan dalam penelitian ini adalah reliable sebagai alat ukur.

2). Instrumen Reability (X2)

Berikut hasil uji reabilitas instrument Reability dengan tujuh butir item pertanyaan adalah sebagai berikut:

Tabel 8

Hasil Uji Reablity instrument Reability

\begin{tabular}{ccc}
\hline Item & Cronbach Alpha & Keterangan \\
\hline Pertanyaan 1 & $0, \mathbf{6 1 3}$ & Reliabel \\
\hline Pertanyaan 2 & $0, \mathbf{6 2 6}$ & Reliabel \\
\hline Pertanyaan 3 & $0, \mathbf{6 0 2}$ & Reliabel \\
\hline Pertanyaan 4 & $0, \mathbf{5 8 5}$ & Tidak Reliabel \\
\hline Pertanyaan 5 & 0.597 & Tidak Reliabel \\
\hline Pertanyaan 6 & $0, \mathbf{5 6 4}$ & Tidak Reliabel \\
\hline Pertanyaan 7 & $0, \mathbf{6 1 6}$ & Reliabel \\
\hline
\end{tabular}

Sumber : data hasil penelitian 2019 yang telah di olah 
Available Online at : journal.stieamkop.ac.id/seiko

"Vol 3, No 1 (2019): July - Desember"

Pada tabel di atas, hasil uji reliabilitas menunjukkan bahwa sebagian item pertanyaan pada variable reability (X2) mempunyai nlai Cronbach Alpha di atas 0,60,meskipun pada pertanyaan no 4,5 dan6 nilai cronbach Alpha < 0,60 .namun dapat dikatakan bahwa secara totalitas semua pertanyaan dari kuesioner yang digunakan dalam penelitian ini adalah reliable sebagai alat ukur di mana nilai cronbach alpha secara keseluruhan pada tabel $>0,60$ yakni cronbach alpha 0,617 >0,60.

3). Instrumen Responsive (X3)

Berikut hasil uji reabilitas instrument Responsive dengan lima butir item pertanyaan adalah sebagai berikut:

Tabel 9

Hasil Uji Reablity instrument Reability

\begin{tabular}{ccc}
\hline Item & Cronbach Alpha & Keterangan \\
\hline Pertanyaan 1 & $0, \mathbf{6 0 2}$ & Reliabel \\
\hline Pertanyaan 2 & $0, \mathbf{6 0 0}$ & Reliabel \\
\hline Pertanyaan 3 & $0, \mathbf{5 9 6}$ & Tidak Reliabel \\
\hline Pertanyaan 4 & $0, \mathbf{5 9 0}$ & Tidak Reliabel \\
\hline Pertanyaan 5 & $0 . \mathbf{5 8 7}$ & Tidak Reliabel \\
\hline \multicolumn{2}{r}{ Sumber : data hasil penelitian 2019 yang telah di olah }
\end{tabular}

Pada tabel di atas,hasil uji Responsive menunjukkan bahwa pada item pertanyaan no 1 dan2 nilai cronbach alpha $\geq 0,60$ namun pada item pertanyaan no 3, 4 dan 5 nilai cronbach alpha $\leq 0,60$ meskipun demikian secara keseluruhan item pertanyaan $X 3$ pada kuesioner yang digunakan dalam penelitian ini adalah reliable sebagai alat ukur. Karena secara keseluruhan nilai cronbach alpha pada variabel responsive adalah 0,608 yang berarti nilai cronbach alpha $\geq 0,60$ (lihat Tabel 1.9)

4). Instrumen Assurance (X4)

Berikut hasil uji reabilitas instrument Assurance dengan lima butir item pertanyaan adalah sebagai berikut : 
Available Online at : journal.stieamkop.ac.id/seiko

"Vol 3, No 1 (2019): July - Desember"

Tabel 10

Hasil Uji instrument Reability

\begin{tabular}{ccc}
\hline Item & Cronbach Alpha & Keterangan \\
\hline Pertanyaan 1 & $0, \mathbf{6 9 1}$ & Reliabel \\
\hline Pertanyaan 2 & $0, \mathbf{6 4 8}$ & Reliabel \\
\hline Pertanyaan 3 & $0, \mathbf{6 2 3}$ & Reliabel \\
\hline Pertanyaan 4 & $0, \mathbf{6 1 7}$ & Reliabel \\
\hline Pertanyaan 5 & $0 . \mathbf{6 0 4}$ & Reliabel
\end{tabular}

Sumber : data hasil penelitian 2019 yang telah di olah

Pada tabel di atas, hasil uji Responsive menunjukkan bahwa semua item pertanyaan dari variabel Assurance (X4) adalah reliable dimana nilai cronbach alfa $\geq 0,60$ sehingga dapat digunakan sebagai alat ukur dalam penelitian

5). Instrumen Emphaty (X5)

Berikut hasil uji reabilitas instrument Emphaty dengan lima butir item pertanyaan adalah sebagai berikut:

Tabel 11

Hasil Uji instrument Emphaty

\begin{tabular}{ccc}
\hline Item & Cronbach Alpha & Keterangan \\
\hline Pertanyaan 1 & 0,751 & Reliabel \\
\hline Pertanyaan 2 & 0,772 & Reliabel \\
\hline Pertanyaan 3 & 0,737 & Reliabel \\
\hline Pertanyaan 4 & 0,759 & Reliabel \\
\hline Pertanyaan 5 & 0.740 & Reliabel \\
\hline \multicolumn{2}{r}{ Sumber : data hasil penelitian 2019 yang telah di olah }
\end{tabular}

Pada tabel di atas,hasil uji instrument Emphaty menunjukkan bahwa semua item pertanyaan pada variable Emphaty (X5) mempunyai nilai Cronbach Alpha di atas 0,60 sehingga dapat dikatakan bahwa semua pertanyaan dari kuesioner yang digunakan dalam penelitian ini adalah reliable sebagai alat ukur. 
Available Online at : journal.stieamkop.ac.id/seiko "Vol 3, No 1 (2019): July - Desember"

\section{PEMBAHASAN}

1. Uji Asumsi Klasik

Uji asumsi klasik yang digunakan untuk mengetahui pelanggaran terhadap asumsi klasik regresi berganda. Apabila tiak terjadi pelanggaran yang mendasari model regresi berganda, maka model yang dianalisis yang diajukan sudah BLUE ( Best LinearUnbias Estimator)

a) Uji Normalitas

Menurut Ghozali (2011) uji normalitasberhubungan dengan salah satu asumsi dasar analisis rgresi berganda,yaitu variabel-variabel indenpenden dan dependent harus berdistribusi normal atau mendekati normal. Untuk menguji kenormalitasan distribusi data, salah satunya dapat dilakukan dengan Kolmogorav-Smirnov (K-S) dengan melihat nilai signifikansi variable > 0,05 pada taraf signifikan alpha $5 \%$,maka menunjukkan distribusi data normal. Hasil normalitas pada msing-masing variabel dapat dilihat pada tabel di bawah ini :

Tabel 12. Hasil Uji Normalitas

\section{One-Sample Kolmogorov-Smirnov Test}

\begin{tabular}{llr} 
& & \multicolumn{1}{c}{$\begin{array}{c}\text { Unstandardized } \\
\text { Residual }\end{array}$} \\
\hline $\mathrm{N}$ & & 50 \\
\hline Normal Parameters & & .0000000 \\
\cline { 2 - 3 } & $\begin{array}{l}\text { Mean } \\
\text { Std. }\end{array}$ & 4.23800210 \\
\hline Most Extreme Differences & Deviation & .109 \\
\cline { 2 - 3 } & Absolute & .049 \\
\cline { 2 - 3 } & Positive & -.109 \\
\cline { 2 - 3 } & Negative & .109 \\
\hline Test Statistic & & $.192^{\mathrm{c}}$ \\
\hline Asymp. Sig. (2-tailed) & & \\
\hline
\end{tabular}

Berdasarkan hasil uji normalitas di atas, dapat dilihat bahwa nilai signifikan untuksemua variable baik variable independent maupun dependent lebih besar dari 0,05 Dengan demikian dapat di simpulkan bahwa nilai residual berdistribusi dengan normal. 
Available Online at : journal.stieamkop.ac.id/seiko "Vol 3, No 1 (2019): July - Desember"

\section{b) Uji Multikolinieritas}

Untuk mengetahui ada tidaknya multikolinearitas dapat dilakukan dengan melihat Value Inflation Factor (VIF) pada model regresi. Apabila nilai VIF >10, maka terjadi multikolinearitas. Sebaliknya jika VIF $<10$, tidak terjadi multikolinearitas ( Wijaya 2009 ), Penelitian ini melakukan uji multikolinearitas dengan melihat Value Inflation Factor (VIF) pada model regresi sepertipada tabel 2 di bawah ini : 
Available Online at : journal.stieamkop.ac.id/seiko

"Vol 3, No 1 (2019): July - Desember"

Hasil Uji Multikolinearitas

\begin{tabular}{|c|c|c|c|}
\hline \multirow[b]{2}{*}{ NO } & \multirow[b]{2}{*}{ Variabel } & \multicolumn{2}{|c|}{ Collinearity Statistik } \\
\hline & & Tolerance & VIF \\
\hline 1 & Tangibe (X1) & 0,463 & 2,161 \\
\hline 2 & Reability ( X2) & 0,221 & 4,531 \\
\hline 3 & Responsive ( X3) & 0,920 & 1,087 \\
\hline 4 & Assurance (X4) & 0,225 & 4,453 \\
\hline 5 & Emphaty (X5) & 0,463 & 2,161 \\
\hline
\end{tabular}

Berdasarkan tabel 13 terlihat bahwa nilai tolerance dari semua variabel bebas mempunyai hasil uji multikolinearitas dengan menggunakan uji VIF menunjukkan variabel bebas yang ada dengan nilai VIF masing-masing variabel $<10$, menunjukkan bahwa ke lima variabel tersebut tidak mengalami masalah multikolinearitas.

\section{Uji Regresi Berganda}

Penelitian ini menggunakan $\mathrm{Uji}$ analisis regresi berganda untuk mengetahui pengaruh variabel Servis Quality yang terdiri dari tangibel (X1), Reability (X2), Responsive(X3),Assurance (X4), Emphaty (X5) terhadap strategi pemasaran sebagai variabel dependent $(\mathrm{Y})$. Dengan formula yang digunakan adalah sebagai berikut :

$Y=a+b 1 \times 1+b 2 \times 2+b 3 \times 3+b 4 \times 4+b 5 \times 5+b 3 \times 3 \ldots$

Keterangan:

Y $\quad$ : Variabel dependent ( nilai yang diprediksikan)

$\mathrm{X} 1, \mathrm{X} 2, \mathrm{X} 3, \mathrm{X} 4, \mathrm{X} 5$ : Variabel independent ( nilai yanmempengaruhi)

a $\quad: k o n s t a n t a($ nilaiY'apabila $X 1, X 2 \ldots . . X n=0$ )

b : koefesien regresi( nilai peningkatan ataupun penurunan

Berdasarkan hail olah data SPSS 24, diperoleh hasil analisis regresi linear berganda dapat dilihat pada tabel dibawah ini 
Available Online at : journal.stieamkop.ac.id/seiko

"Vol 3, No 1 (2019): July - Desember"

Tabel 14

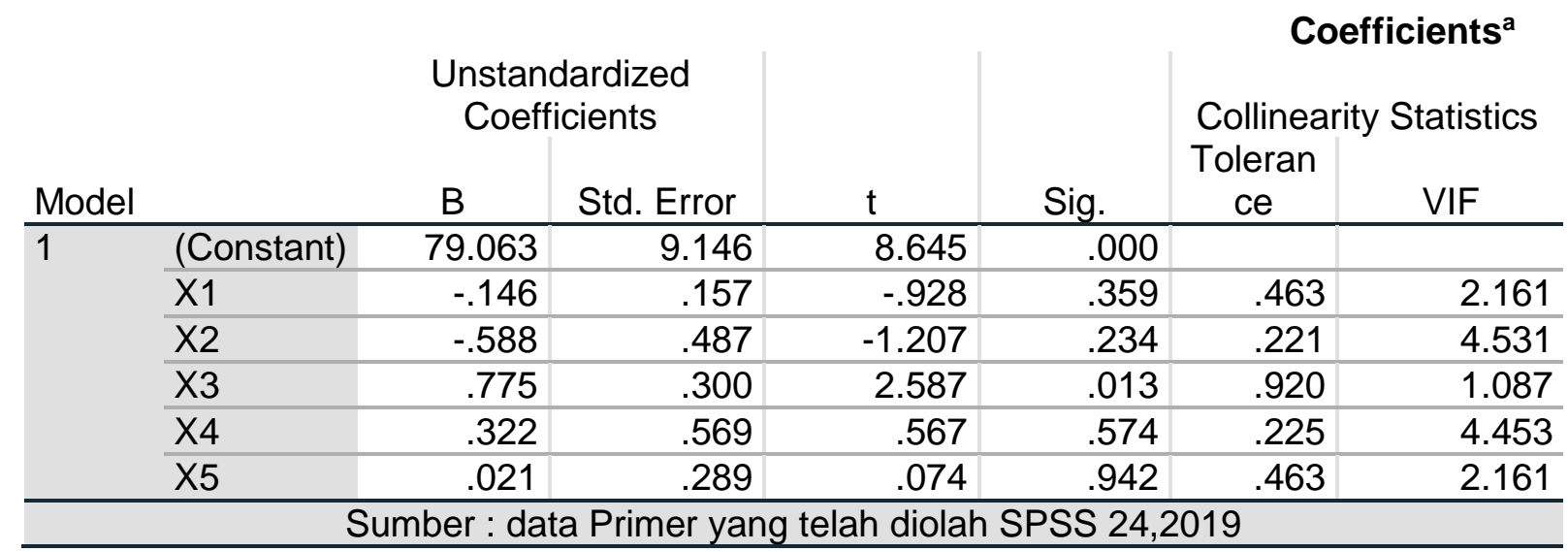

Dari hasil Regresi Linear berganda berdasarkan tabel diperoleh persamaan

regresi berganda sebagai berikut :

$Y=79.063-0,146-0,588+0,775+0.322+0,021+e$

Dari persamaan regresi di atas dapat di interpretasikan sebagai berikut :

1. Konstanta sebesar 79.063 artinya bahwa pengaruh serqual quality $(X)$ yang terdiri dari Tangibel (X1),Reability(X2), Responsive (X3),Assurance(X4) dan Emphaty (X5) bernilai nol,maka akan mempengaruhi strategi pemasaran $(Y)$ sebesar 79.063

2. pada variabel tangible (X1) memiliki arah yang berlawanan yaitu $-0,146$ , Hal ini berarti jika variable tangible turun sebesar -0,146 maka strategi pemasaran juga turun sebesar - 0,146 yang berarti variable tangible tidak berpengaruh terhadap strategi pemasaran pantai wakka disebabkan karena dimensi tangible yang ada di pantai wakka yang berupa pelayan fisik seperti bangunan gazebo wc,kurang maksimal menyebabkan strategi pemasaran turun sebesar - 0,146, sehingga perlu mendapat perhatian khusus bagi pihak pengelola untuk meningkatkan produk-produk wisata dikawasan pantai Wakka

3. Variabel reability((X2) keofesien regresi memiliki arah yang berlawanan -0,588 .maka strategi pemasaran yang diterapkan menurun. Hal ini berarti jika variable reability turun sebesar $-0,588$ maka strategi pemasaran juga turun sebesar _0,588. Hal ini disebabkan karetingkat reability dengan kemampuan pemberian pelayanan yang dijanjikan 
Available Online at : journal.stieamkop.ac.id/seiko "Vol 3, No 1 (2019): July - Desember"

secara akurat dan handal kepada pengunjung turun sebesar-0,588 maka strategi pemasarannya juga turun sebsar -0,588,maka perlu mendapat perhatian khusus bagi pihak pengelola untuk meningkatkan strategi pemasaran dikawasan pantai wakka.

4. Variable responsive (X3) koefisien regresi sebesar 0,755,yang berarti menunjukkan hubungan yang searah. berarti jika variable responsive meningkat sebesar 0,755 maka strategi pemasaran juga meningkat sebesar 0,755. Hal ini berarti variable responsive berpengaruh positif terhadap strategi pemasaran di karenakan bahwa respon yang cepat dan tepat dari pihak pengelola dan masyarakat memberikan daya tarik yang besar bagi wisatawan untuk berkunjung ke pantai wakka sehingga merupakan salah satu strategi pemasaran yang lebih dimaksimalkan.

5. Variabel Assurance (X4) memiliki koefisien regresi sebesar 0,322 yang berarti memiliki hubungan yang searah sehingga dapat di simpulkan bahwa assurance meningkat sebesar 0,322 maka strategi pemasaran meningkat sebesar 0,322 . Hal ini di karenakan Assurance merupakan sebuah jaminan bagi bagi wisatawan yang penuh dengan rasa percaya dan kenyakinan akan keselamatannya dalam menikmati destinasi pantai wakka merupakan strategi pemasaran yang tepat dan efektif untuk lebih dimaksimalkan dikawasan pantai wakka

6. Variabel Emphaty (X5) dengan arah yang searah dengan koefisien regresi sebesar 0,21 yang berarti apabila variable emphaty naik sebesar 1\% maka strategi pemasaran meningkat sebesar 0,21 Dengan asumsi bahwa variable Emphaty dalam keadaan konstan (cateris paribus) ,dengan adanya pengaruh positif ini,berarti bahwa variable emphaty mencakup kepedulian serta perhatian masyarakat sebagai pengelola merupakan aspek penting yang diterapkan dalam strategi pemasaran objek wisata pantai wakka dalam meningkatkan kualitas ekternal dan internal pantai wakka sebagai upaya peningkatan strategi pemasaran wisata alam pantai wakka 
Available Online at : journal.stieamkop.ac.id/seiko "Vol 3, No 1 (2019): July - Desember"

\section{Analisis Korelasi Ganda}

Hasil regresi dapat dilihat pada tabel di bawah ini :

\begin{tabular}{|c|c|c|c|c|c|}
\hline \multicolumn{6}{|c|}{ Model Summaryb } \\
\hline $\begin{array}{l}\text { Mod } \\
\text { el }\end{array}$ & $\mathrm{R}$ & $\begin{array}{c}\mathrm{R} \\
\text { Square }\end{array}$ & $\begin{array}{l}\text { Adjusted R } \\
\text { Square }\end{array}$ & $\begin{array}{l}\text { Std. Error of } \\
\text { the Estimate }\end{array}$ & $\begin{array}{l}\text { Durbin- } \\
\text { Watson }\end{array}$ \\
\hline 1 & $.408^{\mathrm{a}}$ & .167 & .072 & 4.47232 & 2.066 \\
\hline \multicolumn{6}{|c|}{ Berdasarkan tabel diatas di peroleh nilai $\mathrm{R}$ sebsar 0,408 yang berarti terleta } \\
\hline
\end{tabular}

Uji Simultan (Uji F)

Hasil uji f dapat dilihat pada tabel hasil regresi di bawah ini ::

Sumber : Data Primer yang telah diolah SPSS ,2019

\begin{tabular}{|c|c|c|c|c|c|c|}
\hline \multirow[b]{2}{*}{ Model } & & \multicolumn{3}{|c|}{ ANOVA $^{a}$} & \multirow[b]{2}{*}{$\mathrm{F}$} & \multirow[b]{2}{*}{ Sig. } \\
\hline & & $\begin{array}{l}\text { Sum of } \\
\text { Squares }\end{array}$ & Df & $\begin{array}{l}\text { Mean } \\
\text { Square }\end{array}$ & & \\
\hline 1 & $\begin{array}{l}\text { Regressi } \\
\text { on }\end{array}$ & 176.248 & 5 & 35.250 & 1.762 & $.141^{b}$ \\
\hline & Residual & 880.072 & 44 & 20.002 & & \\
\hline & Total & 1056.320 & 49 & & & \\
\hline
\end{tabular}


Available Online at : journal.stieamkop.ac.id/seiko "Vol 3, No 1 (2019): July - Desember"

Berdasarkan table di atas, di peroleh $\mathrm{F}$ hitung sebesar 1.762 dengan nilai $\mathrm{F}$ tabel berada pada taraf signifikansi $a=0,05$ dengan $n-k-1$ di mana $n$ adalah jumlah respondent, $\mathrm{k}$ adalah jumlah variable independent) maka $n-k-1=50-5-1=$ 44, maka diperoleg $F$ tabel sebesar 3,209 sehingga dapat di simpulkan bahwa $F$ hitung $<\mathrm{F}$ tabel yaitu $1.762<3,209$ yang berarti bahwa Ho di terima dan $\mathrm{Ha}$ di tolak maka secara bersama-sama variable tangible,reability, responsive ,assurance dan emphaty tidak berpengaruh terhadap strategi pemasaran pada objek wisata pantai wakka. Hal ni disebabkan karena kondisi riil pantai wakka sejak ramai dikunjungi wisatawan tahun 2012 hingga sekarang tahun 2019, potensi yang ada belum dikelola secara maksimal,unsuru-unsur serqual hampir sama sekali tidak ada.Hal ini disebabkan karena tidak adanya kerja sama antara masyarakat setempat sebagai pengelola dengan pemerintah setempat dalam memanfaatkan kekuatan internal yang dimiliki kawasan pantai wakka sebagai objek wisata demikian halnya juga dengan pengelolaan faktor eksternal yang tidak mendukung pengembangan pantai wakka sebagai industri wisata di kabupaten Pinrang .

\section{Pengujian secara Parsial ( Uji t)}

Dalam menentukan criteria uji t di mana Ho di tolak dan dan Ha di terima jika t hitung $>\mathrm{t}$ tabel atau sig $<0,05$ dan sebaliknya Ho diterima dan $\mathrm{Ha}$ di tolak jika t tabel $<$ t hitung atau sig $>0,05$. Berikut tabel uji t di bawah ini

\begin{tabular}{lllll}
\hline Variable & t-hitung & t- table & $\begin{array}{l}\text { t-signifikan } \\
\text { (probabiltas) }\end{array}$ & Keterangan \\
\hline X1 & -.928 & 2.015 & .359 & Tdk signfikan \\
\hline X2 & -1.207 & 2.015 & 234 & Tdk signfikan \\
\hline X3 & 2.587 & 2.015 & .013 & signfikan \\
\hline X4 & .567 & 2.015 & 574 & Tdk signfikan \\
\hline X5 & .074 & 2.015 & 942 & Tdk signfikan \\
\hline
\end{tabular}

Sumber data Primer yang telah di olah SPSS 24,2019 
Available Online at : journal.stieamkop.ac.id/seiko "Vol 3, No 1 (2019): July - Desember"

Berdasarkan hasil uji t pada tabel maka secara parsial dapat dilihat bahwa $\mathrm{t}$ hitung $<\mathrm{t}$ table , maka kesimpulannya adalah bahwa Ho di terima dan $\mathrm{Ha}$ di tolak yang berarti bahwa variable $\mathrm{X} 1, \mathrm{X} 2, \mathrm{X} 3$ dan $\mathrm{X} 4$ tidak berpengaruh secara signifikan pada strategi pemasaran di pantai wakka kabupaten pinrang hal ini disebabkan secara reality bahwa pantai wakka sejak berkembang menjadi destinasi wisata 2012 hingga tahun 2015 mengalami penurunan kunjungan wisata yang di sebabkan karena tidak berkembangnya produk -produk wisata yang ada dikawasan pantai . Pantai wakka secara eksternal dan internal tidak mengalami perubahan dan peningkatan produk,produk-produk yang ada hampir semuanya membutuhkan renovasi ulang.

Tabel 13

Hasil Uji Multikolinearitas

\begin{tabular}{|c|c|c|c|}
\hline \multirow[b]{2}{*}{ NO } & \multirow[b]{2}{*}{ Variabel } & \multicolumn{2}{|c|}{ Collinearity Statistik } \\
\hline & & Tolerance & VIF \\
\hline 1 & Tangibe (X1) & 0,463 & 2,161 \\
\hline 2 & Reability ( X2) & 0,221 & 4,531 \\
\hline 3 & Responsive ( X3) & 0,920 & 1,087 \\
\hline 4 & Assurance (X4) & 0,225 & 4,453 \\
\hline 5 & Emphaty ( X5) & 0,463 & 2,161 \\
\hline
\end{tabular}

Berdasarkan tabel 13 terlihat bahwa nilai tolerance dari semua variabel bebas mempunyai hasil uji multikolinearitas dengan menggunakan uji VIF menunjukkan variabel bebas yang ada dengan nilai VIF masing-masing variabel $<10$, menunjukkan bahwa ke lima variabel tersebut tidak mengalami masalah multikolinearitas.

2. Uji Regresi Berganda

Penelitian ini menggunakan Uji analisis regresi berganda untuk mengetahui pengaruh variabel Servis Quality yang terdiri dari tangibel (X1), Reability (X2), Responsive(X3),Assurance (X4), Emphaty (X5) terhadap strategi pemasaran sebagai variabel dependent $(Y)$. Dengan formula yang digunakan adalah sebagai berikut :

$Y=a+b 1 \times 1+b 2 \times 2+b 3 \times 3+b 4 \times 4+b 5 \times 5+b 3 \times 3 \ldots$

Keterangan: 
Available Online at : journal.stieamkop.ac.id/seiko

\section{"Vol 3, No 1 (2019): July - Desember"}

$\mathrm{X} 1, \mathrm{X} 2, \mathrm{X} 3, \mathrm{X} 4, \mathrm{X} 5$ : Variabel independent ( nilai yanmempengaruhi)

a $\quad: k o n s t a n t a($ nilaiY'apabila $X 1, X 2 \ldots . X n=0$ )

b : koefesien regresi( nilai peningkatan ataupun penurunan

Berdasarkan hail olah data SPSS 24, diperoleh hasil analisis regresi linear berganda dapat dilihat pada tabel dibawah ini

Tabel 14

\begin{tabular}{|c|c|c|c|c|c|c|c|}
\hline \multirow[b]{2}{*}{ Mod } & \multicolumn{3}{|c|}{$\begin{array}{l}\text { Unstandardized } \\
\text { Coefficients }\end{array}$} & \multirow[b]{2}{*}{$\mathrm{t}$} & \multirow[b]{2}{*}{ Sig. } & Collinea & ients ${ }^{a}$ \\
\hline & & B & Std. Error & & & $\begin{array}{c}\text { Toleran } \\
\text { ce }\end{array}$ & \\
\hline 1 & (Constant) & 79.063 & 9.146 & 8.645 & .000 & & \\
\hline & $\mathrm{X} 1$ & -.146 & .157 & -.928 & .359 & .463 & 2.161 \\
\hline & $x 2$ & -.588 & .487 & -1.207 & .234 & .221 & 4.531 \\
\hline & $x 3$ & .775 & .300 & 2.587 & .013 & .920 & 1.087 \\
\hline & $X 4$ & .322 & .569 & .567 & .574 & .225 & 4.453 \\
\hline & $x 5$ & .021 & .289 & .074 & .942 & .463 & 2.161 \\
\hline
\end{tabular}

Dari hasil Regresi Linear berganda berdasarkan tabel diperoleh persamaan regresi berganda sebagai berikut :

$Y=79.063-0,146-0,588+0,775+0.322+0,021+e$

Dari persamaan regresi di atas dapat di interpretasikan sebagai berikut :

7. Konstanta sebesar 79.063 artinya bahwa pengaruh serqual quality $(X)$ yang terdiri dari Tangibel (X1), Reability(X2), Responsive (X3),Assurance(X4) dan Emphaty (X5) bernilai nol,maka akan mempengaruhi strategi pemasaran $(Y)$ sebesar 79.063

8. pada variabel tangible (X1) memiliki arah yang berlawanan yaitu $-0,146$ , Hal ini berarti jika variable tangible turun sebesar -0,146 maka strategi pemasaran juga turun sebesar - 0,146 yang berarti variable tangible tidak berpengaruh terhadap strategi pemasaran pantai wakka disebabkan karena dimensi tangible yang ada di pantai wakka yang berupa pelayan fisik seperti bangunan gazebo wc,kurang maksimal menyebabkan strategi pemasaran turun sebesar - 0,146, sehingga perlu mendapat perhatian khusus bagi pihak pengelola untuk meningkatkan produk-produk wisata dikawasan pantai Wakka 
Available Online at : journal.stieamkop.ac.id/seiko "Vol 3, No 1 (2019): July - Desember"

9. Variabel reability ((X2) keofesien regresi memiliki arah yang berlawanan $-0,588$.maka strategi pemasaran yang diterapkan menurun. Hal ini berarti jika variable reability turun sebesar -0,588 maka strategi pemasaran juga turun sebesar_0,588. Hal ini disebabkan karetingkat reability dengan kemampuan pemberian pelayanan yang dijanjikan secara akurat dan handal kepada pengunjung turun sebesar - 0,588 maka strategi pemasarannya juga turun sebsar -0,588, maka perlu mendapat perhatian khusus bagi pihak pengelola untuk meningkatkan strategi pemasaran dikawasan pantai wakka.

10. Variable responsive (X3) koefisien regresi sebesar 0,755 ,yang berarti menunjukkan hubungan yang searah. berarti jika variable responsive meningkat sebesar 0,755 maka strategi pemasaran juga meningkat sebesar 0,755 . Hal ini berarti variable responsive berpengaruh positif terhadap strategi pemasaran di karenakan bahwa respon yang cepat dan tepat dari pihak pengelola dan masyarakat memberikan daya tarik yang besar bagi wisatawan untuk berkunjung ke pantai wakka sehingga merupakan salah satu strategi pemasaran yang lebih dimaksimalkan.

11. Variabel Assurance (X4) memiliki koefisien regresi sebesar 0,322 yang berarti memiliki hubungan yang searah sehingga dapat di simpulkan bahwa assurance meningkat sebesar 0,322 maka strategi pemasaran meningkat sebesar 0,322. Hal ini di karenakan Assurance merupakan sebuah jaminan bagi bagi wisatawan yang penuh dengan rasa percaya dan kenyakinan akan keselamatannya dalam menikmati destinasi pantai wakka merupakan strategi pemasaran yang tepat dan efektif untuk lebih dimaksimalkan dikawasan pantai wakka

12. Variabel Emphaty (X5) dengan arah yang searah dengan koefisien regresi sebesar 0,21 yang berarti apabila variable emphaty naik sebesar 1\% maka strategi pemasaran meningkat sebesar 0,21 Dengan asumsi bahwa variable Emphaty dalam keadaan konstan (cateris paribus) ,dengan adanya pengaruh positif ini,berarti bahwa variable emphaty mencakup kepedulian serta perhatian masyarakat sebagai pengelola merupakan aspek penting yang diterapkan dalam strategi pemasaran 
Available Online at : journal.stieamkop.ac.id/seiko "Vol 3, No 1 (2019): July - Desember"

objek wisata pantai wakka dalam meningkatkan kualitas ekternal dan internal pantai wakka sebagai upaya peningkatan strategi pemasaran wisata alam pantai wakka

\section{Analisis Korelasi Ganda}

Hasil regresi dapat dilihat pada tabel di bawah ini :

\begin{tabular}{|c|c|c|c|c|c|}
\hline \multicolumn{6}{|c|}{ Model Summaryb } \\
\hline $\begin{array}{l}\text { Mod } \\
\text { el }\end{array}$ & $\mathrm{R}$ & $\begin{array}{c}\mathrm{R} \\
\text { Square }\end{array}$ & $\begin{array}{l}\text { Adjusted R } \\
\text { Square }\end{array}$ & $\begin{array}{l}\text { Std. Error of } \\
\text { the Estimate }\end{array}$ & $\begin{array}{l}\text { Durbin- } \\
\text { Watson }\end{array}$ \\
\hline 1 & $.408^{a}$ & .167 & .072 & 4.47232 & 2.066 \\
\hline
\end{tabular}

Berdasarkan tabel diatas di peroleh nilai $\mathrm{R}$ sebsar 0,408 yang berarti terletak pada 0,40-0,599 hal ini menunjukkan bahwa terjadi hubungan yang sedang antara variabel independent yaitu tangible (X1), Reability(X2), Responsive (X3), Assurance (X4), Emphaty (X5) dengan variable dependent.(Y) Yaitu strategi pemasaran

\section{Uji Simultan (Uji F)}

Hasil uji $f$ dapat dilihat pada tabel hasil regresi di bawah ini ::

Sumber : Data Primer yang telah diolah SPSS ,2019

\begin{tabular}{|c|c|c|c|c|c|c|}
\hline \multirow[b]{2}{*}{ Model } & & \multicolumn{3}{|c|}{ ANOVA $^{a}$} & \multirow[b]{2}{*}{$F$} & \multirow[b]{2}{*}{ Sig. } \\
\hline & & $\begin{array}{l}\text { Sum of } \\
\text { Squares }\end{array}$ & Df & $\begin{array}{l}\text { Mean } \\
\text { Square }\end{array}$ & & \\
\hline 1 & $\begin{array}{l}\text { Regressi } \\
\text { on }\end{array}$ & 176.248 & 5 & 35.250 & 1.762 & $.141^{\mathrm{b}}$ \\
\hline & Residual & 880.072 & 44 & 20.002 & & \\
\hline & Total & 1056.320 & 49 & & & \\
\hline
\end{tabular}


Available Online at : journal.stieamkop.ac.id/seiko "Vol 3, No 1 (2019): July - Desember"

Berdasarkan table di atas, di peroleh $\mathrm{F}$ hitung sebesar 1.762 dengan nilai $\mathrm{F}$ tabel berada pada taraf signifikansi $a=0,05$ dengan $n-k-1$ di mana $n$ adalah jumlah respondent, $\mathrm{k}$ adalah jumlah variable independent) maka $n-k-1=50-5-1=$ 44, maka diperoleg $F$ tabel sebesar 3,209 sehingga dapat di simpulkan bahwa $F$ hitung $<\mathrm{F}$ tabel yaitu $1.762<3,209$ yang berarti bahwa Ho di terima dan $\mathrm{Ha}$ di tolak maka secara bersama-sama variable tangible,reability, responsive ,assurance dan emphaty tidak berpengaruh terhadap strategi pemasaran pada objek wisata pantai wakka. Hal ni disebabkan karena kondisi riil pantai wakka sejak ramai dikunjungi wisatawan tahun 2012 hingga sekarang tahun 2019, potensi yang ada belum dikelola secara maksimal,unsuru-unsur serqual hampir sama sekali tidak ada.Hal ini disebabkan karena tidak adanya kerja sama antara masyarakat setempat sebagai pengelola dengan pemerintah setempat dalam memanfaatkan kekuatan internal yang dimiliki kawasan pantai wakka sebagai objek wisata demikian halnya juga dengan pengelolaan faktor eksternal yang tidak mendukung pengembangan pantai wakka sebagai industri wisata di kabupaten Pinrang .

\section{Pengujian secara Parsial ( Uji t)}

Dalam menentukan criteria uji t di mana Ho di tolak dan dan Ha di terima jika t hitung $>\mathrm{t}$ tabel atau sig $<0,05$ dan sebaliknya Ho diterima dan $\mathrm{Ha}$ di tolak jika t tabel $<$ t hitung atau sig $>0,05$. Berikut tabel uji t di bawah ini

\begin{tabular}{lllll}
\hline Variable & t-hitung & t- table & $\begin{array}{l}\text { t-signifikan } \\
\text { (probabiltas) }\end{array}$ & Keterangan \\
\hline X1 & -.928 & 2.015 & .359 & Tdk signfikan \\
\hline X2 & -1.207 & 2.015 & 234 & Tdk signfikan \\
\hline X3 & 2.587 & 2.015 & .013 & signfikan \\
\hline X4 & .567 & 2.015 & 574 & Tdk signfikan \\
\hline X5 & .074 & 2.015 & 942 & Tdk signfikan \\
\hline
\end{tabular}

Sumber data Primer yang telah di olah SPSS 24,2019 
Available Online at : journal.stieamkop.ac.id/seiko "Vol 3, No 1 (2019): July - Desember"

Berdasarkan hasil uji t pada tabel maka secara parsial dapat dilihat bahwa t hitung < t table , maka kesimpulannya adalah bahwa Ho di terima dan $\mathrm{Ha}$ di tolak yang berarti bahwa variable $\mathrm{X} 1, \mathrm{X} 2, \mathrm{X} 3$ dan $\mathrm{X} 4$ tidak berpengaruh secara signifikan pada strategi pemasaran di pantai wakka kabupaten pinrang hal ini disebabkan secara reality bahwa pantai wakka sejak berkembang menjadi destinasi wisata 2012 hingga tahun 2015 mengalami penurunan kunjungan wisata yang di sebabkan karena tidak berkembangnya produk -produk wisata yang ada dikawasan pantai . Pantai wakka secara eksternal dan internal tidak mengalami perubahan dan peningkatan produk, produk-produk yang ada hampir semuanya membutuhkan renovasi ulang.

\section{SIMPULAN}

1. Pada dimensi tangible dari hasil regresi berganda memiliki arah yang berlawanan yang secara berarti Secara umum serqual pada dimensi tangible di kawasan wisata pantai wakka masih kurang maksimal karena memiliki nilai gap negative - 0,146 atau belum sesuai dengan harapan wisatawan yang berkunjung di akibatkan karena lingkungan fisik yang kurang meliputi Fasilitas produk yang dimiliki, sarana kuliner,rumah peristirahatan (gazebo), toilet ramah lingkungan,lahan parkir,sarana ibadah belum sesuai permintaan pasar. Yang mengurangi image di mata wisatawan selaku konsumen.Untuk mengatasi masalah ini strategi pemasaran yang dapat dilakukan oleh pihak masyarakat selaku pengelola adalah melakukan diversifikasi produk dikawasan pantai wakka.

2. Pada unsur reability dari hasil regresi berganda juga memiliki arah yang berlawanan yang berarti secara umum kualitas pelayanan dimensi tangible dikawasan pantai wakka belum maksimal karena memiliki nilai sebesar -0,588 belum menggambarkan keinginan konsumen dalam pemberian jasa pelayanan yang handal tidak sesuai dengan standar atau spesifikasi dari kebutuhan strategi pemasaran dimana terjadi kesenjangan yang disebabkan oleh penyedia jasa dalam hal ini masyarakat sebagai pengelola pantai wakka tidak memiliki desain dan standard yangjelas mengenai cara-cara 
Available Online at : journal.stieamkop.ac.id/seiko "Vol 3, No 1 (2019): July - Desember"

penyampaian jasanya,masyarakat/pengelola tidak memahami standar yang di inginkan pengunjung/wisatawan

3. Berdasarkan uji $f$, dan uji t menunjukan bahwa akibat tidak meningkatnya produk wisata yang ada di pantai Wakka menyebabkan servis quality dengan 5 dimensinya yaitu Tangibel, reability, responsive, assurance dan emphaty tidak belum mampu memberikan kemajuan yang signifikan dalam mengoptimalkan potensiyang ada,sehingga diperlukan peningkatan strategi pemasaran yang dapat menjawab kebutuhan wisatawan serta dapat mempertahankan keberlansungan dalam pembangunan pariwisata objek wisata pantai wakka dengan menggunakan prinsip-prinsip paduan strategi pemasaran terpadu yang meliputi paduan produk (semua unsur produk wisata harus ditumbuhkembangkan sehingga mampu bersaing); paduan penyebaran (pendistribusian wisatawan melibatkan semua pihak); paduan komunikasi (sehingga dapat memberikan informasi produk menarik); dan paduan pelayanan (harus baik sehingga produk wisata akan baik pula). ( Sukarni Novita Sari :2016)

\section{ACKNOWLEDGEMENT}

Penelitian ini tentunya tidak dapat terlaksana atau diselesaikan dengan tepat waktu tanpa adanya dukungan dan partisipasi dari berbagai pihak, utamanya pihak yang telah menghibahkan dana penelitian, untuk itu izinkan peneliti mengucapkan terima kasih yang tak terhingga kepada :

1. Kementerian Riset Teknologi dan Pendidikan Tinggi yang telah mempercayakan peneliti dalam melakukan penelitian ini.

2. Abd Rifai Arafah.SE.M.Si Selaku Direktur Akademi Sekretari Manajemen (ASM) Amsir Parepare

3. Ades Asike.S.Kom.MM Selaku Ketua Lembaga Penelitian Pengabdian Masyarakat Akademi Sekretari Manajemen (ASM) Amsir Parepare

4. Firmansyah Hibbu.SH Staf Bagian Akademik dan Kemahasiswaan Akademi Sekretari Manajemen (ASM) Amsir Parepare 
Available Online at : journal.stieamkop.ac.id/seiko

"Vol 3, No 1 (2019): July - Desember"

\section{REFERENSI :}

Alifiana Hafidian Rizkiyani dan Fuad Achmadi, 2016,Strategi Pemasaran Objek Wisata Dengan Pendekatan Servqual Mix Dan Quality Function Deployment (Qfd) (Studi Kasus Di Objek Wisata Pantai Talang Siring Kabupaten Pamekasan). Prosiding Seminar Nasional Manajemen Teknologi XXIV Program Studi MMT-ITS

El Samen, A.A dan M.Alshurideh. 2012. the impact of internal marketing on internal servis quality : A case study in Jordanian Pharmaceutical Company,Internasional Of Journal Business And Management.Vol 7 No 19. Published By Canadian Center Of Science And Education.

Fandy T,Gregorius,Dadi Adriana,2008,Pemasaran Strategik,penerbit Andi,Yogyakarta

Ghozali,2011 ,Aplikasi analisis multivariate dengan program SPSS semarang penerbit Universitas Diponegoro

l'anatut Thoifah,2015,Statistika Pendidikan Dan Metode Penelitian Kuantitatif,(anggota IKAPI Malang)

Kotler, P \& Keller. (2009). Manajemen Pemasaran. Jilid I. Edisi ke 13. Jakarta: Erlangga

Sukarni Novita Sari ,Bijak, Majalah IImiah Institut STIAMI ISSN 1411-0830 Volume XIII, No. 01, Maret 2016

Sugiyono,2017 metode peneltian bisnis,Bandung Alfa beta

Tony Wijaya 2013,metodelogi penelitian ekonomi dan bisnis teori dan praktik, Yogyakarta,Graha IImu 